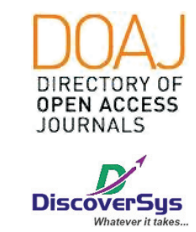

Published by DiscoverSys

\section{Correlation between extracurricular activities and academic performances among preclinical medical students in Udayana University, Bali, Indonesia}

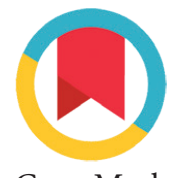

CrossMark

\author{
Muhammad Faisal Putro Utomo, ${ }^{1 *}$ Ida Ayu Dewi Dhyani, ${ }^{1}$ \\ I Gusti Agung Ayu Andra Yusari, ${ }^{1}$ I Putu Hendri Aryadi, ${ }^{1}$ \\ Ni Putu Diah Utami Darmayanti, ${ }^{1}$ I Gde Haryo Ganesha ${ }^{2}$
}

\section{ABSTRACT}

grouped into good and average. Data were analyzed using univariate and bivariate analysis (Chi-Square Test with Cramer's V) on SPSS version 20 for Windows.

Results: From 221 medical students (males 43.9\%; females 56.1\%), $48 \%$ are active participants of extracurricular programs. Fifty-nine medical students had a good GPA and 162 medical students had an average GPA. The mean score of Credit Point of Participation are $116.545 \pm 65.79$ and GPA is $3.3781 \pm 0.282$ (out of possible 4). Our study showed a positive correlation between extracurricular activities and academic performance $(r=0.2 ; p=0.003)$.

Conclusions: Medical students who are active participants in extracurricular programs have better academic performance than those who are passive. Extracurricular activities lead to a positive impact on academic achievement because it can decrease any academic stress and tension, which lead to more productivity in their learning. \begin{abstract}
from the Academic Affair's registered data (Grade Point Average and gender). GPA was the indicator of academic performance and

Background: Medical students are required to develop the ability and enhance the students' performance when facing a real-life situation in the community. It can be developed through an extracurricul aspect. This study was aimed to explore the correlation between Methods: A cross-sectional study was conducted among 221 medical students of Udayana University in the preclinical phase. Data were taken from data collecting by the Student Executive Board for Credit Point of Participation, which was the indicator of extracurricular activities and grouped into active and not active. Data were also taken
\end{abstract}

Keywords: extracurricular activities, academic performances, preclinical, medical students Cite This Article: Utomo, M.F.P., Dhyani, I.A.D., Yusari, I.G.A.A.A., Aryadi, I.P.H., Darmayanti, N.P.D.U., Ganesha, I.G.H. 2019. Correlation between extracurricular activities and academic performances among preclinical medical students in Udayana University, Bali, Indonesia. Intisari Sains Medis 10(3): 588-591. D0I: 10.15562/ism.v10i3.470

\section{INTRODUCTION}

Student, Facult Indonesia

${ }^{2}$ Department of Medical Education, Faculty of Medicine, Udayana University, Bali, Indonesia

${ }^{*}$ Correspondence to: Muhammad Faisal Putro Utomo; Medical Student, Faculty of Medicine, Udayana University, Bali, Indonesia;

mfaisal.utomo@gmail.com

Received: 2019-03-30 Accepted: 2019-08-16 Published: 2019-08-01
The pre-clinical study is not only about curricular activities. There are also extracurricular activities that conducted simultaneously with curricular activities. Curricular activities commonly include lectures, educational activities (small-group discussion, problem-based learning, and team-based learning), and examinations. ${ }^{1}$ Extracurricular activities (or extraacademic activities) are activities outside of the classroom, other than academic tasks, and generally non-mandatory., ${ }^{2,3}$ Extracurricular activities can be in the form of research, teaching, hobbies, community service, social, cultural, religious, and sports activities. These activities can be undertaken inside or outside of the medical school campus. ${ }^{1,4}$

Extracurricular activities are potential media to develop soft skills, including interpersonal and social skills. These soft skills are very closely related to professionalism as a doctor in the future.
Pre-clinical students personally can learn about caring, communication skills, professionalism, collaboration and team working skills, effective time management skills, ethical attitudes, and also leadership by experiential learning which are more effective than only theoretical learning. These skills can affect to learning quality of a person and reach successfulness. Therefore, soft skills are important part in order to enhance achievement in academic performances., ${ }^{2,5-7}$

Based on the aforementioned, this study aims to explore the correlation between extracurricular activities and academic performances among pre-clinical medical students. The result would support either disprove if there were any impact of extracurricular activities on academic performances among pre-clinical medical students in Faculty Medicine of Udayana University. 


\section{METHODS}

\section{Inclusion and Exclusion Criteria}

This study was conducted during 2017 at Faculty of Medicine, Udayana University, located in Bali, Indonesia. The bachelor program of medicine is divided into two phases: pre-clinical (seven semesters) and clinical (three semesters). The targeted sample included all medical students with the admission year 2013 who were on their last year of pre-clinical phase. The reason for such inclusion is because these students already passed all subjects that thaught during the pre-clinical phase of the study and spend a lot of their time to participate in extracurricular activities. The reason for excluding the younger year students was because of two reasons: (1) They were still on the active year in following extracurricular which could alter the result anytime thus made it not beneficial and not valid, and also (2) especially for the first-year student who had lack of sufficient involvement in extracurricular activities due to time is taken to settle down and adjust their college life. Clinical phase students were excluded as their time is mostly spent in the hospitals and on clinically-related activities rather than extracurricular activities.

\section{Data collection}

The data was taken by total sampling and including all medical students with the admission year $2013(n=221)$. The first data was to indicate the extracurricular activities of the sample. Data were taken from data collecting by the Student Executive Board for Credit Point of Participation, which was collected by the sample following any extracurricular activities. The accumulation point of Credit Point of Participation has represented the extracurricular activities during the pre-clinical study. Based on Credit Point of Participation, the sample was divided into two groups; active and not active. The following data was to indicate the academic performance of the sample. Data were taken from registered data of Academic Affair Department. The data were including Grade Point Average (GPA) during the seven semester of pre-clinical study. Based on the GPA, then the sample was grouped into good and average academic performances. The last data were also from registered data of Academic Affair Department, including demographic data (gender, nationality, and class).

\section{Data analysis}

The data which had been collected were analyzed via the Statistical Package for Social Sciences (SPSS) software program v.20. The cut off for accumulation point of Credit Point of Participation was 100 points to simplify the classification of the sample. The sample who had more than 100 points were considered into active student and not active for those who had less than 100 points. The cut-off point for GPA was 3.5 in order to divide the sample into two major academic performance groups. Sample who was above 3.5 was classified into good and under 3.5 into average. Both extracurricular activities and academic performance were analyzed using Chi-Square Test with Cramer's V. Chi-Square Tests are usually used as a method to discover any statistically significant relationship between two categorical variables (nominal variable with either another nominal variable or ordinal variable). Cramer's $\mathrm{V}$ is a Chi-Square based test that used to measure the strength of the correlation. This method has covered the aim of the study. This study has an independent and dependent variable which are: (1) extracurricular activities as an independent variable and (2) academic performances as a dependent variable. In this study, also used univariate analysis to discover statistics of demographic data.

\section{RESULT}

\section{Bivariate Analysis}

Two hundred and twenty-one data of medical students was collected after exclusions. Name, address, and resident registration number of the sample were anonymized. All of these samples were suitable for data analysis. A hundred and twenty-four (56.1\%) of the sample were female, 83.7\% had Indonesian nationality, and 51.1\% were attending Regular class while the rest were attending International class.

Sample who was active in extracurricular activities were $48 \%$ medical students with Mean \pm SD score was $116.5 \pm 65.8$. Meanwhile, the GPA as academic performances representative had Mean \pm SD score $3.37 \pm 0.28$ (maximum score was 4.00). Medical students with good academic performances were $26.7 \%$ while the rest were considered as average.

Table 2 displays there was a significant correlation between extracurricular activities and academic performances $(\mathrm{p} \leq 0.05)$. This result showed that the more active the students in extracurricular activities, the students tend to show better achievement in academic performances and vice versa. However, the correlation between extracurricular activities and academic performance was about 0.15-0.20, which mean the strength was a weak correlation. This weak correlation was minimally acceptable because if one variable increased or decrease, there is a lower possibility to correlate with the other variable. 
Table 1 Baseline characteristics of respondents

\begin{tabular}{lcc}
\hline Variable & Frequency $(\mathbf{n = 2 2 1 )}$ & Percentage (\%) \\
\hline Gender & 97 & 43.9 \\
$\quad$ Female & 124 & 56.1 \\
$\quad$ Male & & \\
Nationality & 185 & 83.7 \\
$\quad$ Indonesia & 36 & 16.3 \\
Foreigner & & \\
Class & 113 & 51.1 \\
$\quad$ Regular & 108 & 48.9 \\
International & & \\
Extracurricular Activities & 106 & 48.0 \\
Active & 115 & 52.0 \\
Not Active & & 26.7 \\
Academic Performances & 59 & 73.3 \\
Good & 162 & \\
Average & & \\
\hline
\end{tabular}

Table 2 Chi-Square Test with Cramer's V between Extracurricular Activities and Academic Performances

\begin{tabular}{lcccc}
\hline \multirow{2}{*}{$\begin{array}{l}\text { Extracurricular } \\
\text { Activities }\end{array}$} & \multicolumn{2}{c}{ Academic Performances } & & \\
\cline { 2 - 3 } & Good & Average & P Value $^{*}$ & Cramer's V** $^{* *}$ \\
\hline Active & 38 & 68 & 0.003 & 0.199 \\
Not Active & 21 & 94 & & \\
\hline
\end{tabular}

* A Pearson Chi-Square Test was performed to correlate between extracurricular activities and academic performances. Statistical significance if $\mathrm{p} \leq 0.05$

"* A Cramer's V measurement was performed to measure the strength of the correlation. Level of Association. $00-.15=$ very weak, $.15-.20=$ weak, $.20-.25=$ moderate, $.25-.30=$ moderately strong, $.30-.35=$ strong, $.35-.40=$ very strong, $.40-.50=$ worrisomely strong, $.50-.99=$ redundant, $1.00=$ perfect relationship
This finding has similarity to the previous study conducted by Almasry et al., that extracurricular showed the same significant correlation with academic achievement. ${ }^{1}$ A study by Lumley et al. stated that participation in research- and teachingrelated extracurricular activities was a significant factor associated with higher academic performances. Slade and Kies found that student who followed sport-based extracurricular activities, scored higher during final examinations. ${ }^{9,10}$ Urlingsstrop et al. surprisingly found that extracurricular activities were also resulting in better achievement during clinical years of medical school. ${ }^{11}$

Extracurricular activities can lead to a positive impact on academic performances. As known, medical education implemented in a stressful environment. This situation happens because medical students were expected to learn a vast amount of concepts and facts with limited time and memory. Hence, stress and burnout progressively occur among both pre-clinical and clinical medical students. Focusing on extracurricular activities, it can be an intermediator to decrease anxiety, stress, and burn out, and also enhancing mental and physical health. Good interpersonal and social skills developed during the following extracurricular activities were enabling students to determine attitude in adapting stressful environment. Lower stress and anxiety level were resulting in increase productivity in their learning; this can lead to better achievement in academic performances. In addition, participation in extracurricular activities leads to a reduction in dropout rates. ${ }^{3,12,13}$

However, a different result was found by Shamsudin et al. in Malaysia, whereas they showed that there was not enough evidence to prove a significant positive correlation between extracurricular activities and academic performances. Nevertheless, the government of the country still emphasizing the importance of incorporating extracurricular activities with curricular activities. ${ }^{13}$

\section{CONCLUSION}

The result showed that generally, the quantity of active and not active students in extracurricular activities was almost balanced. Extracurricular activities seemed to be satisfying to the achievement in academic performances. This correlation most likely linked by stress and burnout reliefs provided by extracurricular activities resulted in better learning abilities and better academic performances. However, further studies with a bigger sample size are recommended to settle with the limitation of this study. Future studies are also needed to 
examine specific extracurricular activities and the outcomes in medical students' performance.

\section{ETHICAL CONSIDERATION}

This study has been obtained ethics approval from the Ethics Committee of Faculty of Medicine, Udayana University, Bali, Indonesia prior to the study conducted.

\section{CONFLICT OF INTEREST}

The authors declare that there is no competing interest regarding the manuscript

\section{FUNDING}

The authors are responsible for the funding of study without the involvement of grant, scholarship, or any other resources of funding.

\section{AUTHOR CONTRIBUTION}

All authors are equally contributed to the study from the conceptual framework, data gathering, data analysis, until reporting the results in this study.

\section{REFERENCES}

1. Almasry M, Kayali Z, Alsaad R, Alhayaza G, Ahmad MS, Obeidat A, et al. Perceptions of preclinical medical students towards extracurricular activities. Int J Med Educ. 2017;8:285-9.

2. Kim SH. Extracurricular activities of medical school applicants. Korean J Med Educ. 2016;28(2):201-7.

3. Fares J, Saadeddin Z, Al Tabosh H, Aridi H, El Mouhayyar C, Koleilat MK, et al. Extracurricular activities associated with stress and burnout in preclinical medical students. J Epidemiol Glob Health. 2015;6(3):177-85.
4. Al-Ansari A, Al-Harbi F, AbdelAziz W, AbdelSalam M, El Tantawi MM, ElRefae I. Factors affecting student participation in extra-curricular activities: A comparison between two Middle Eastern dental schools. Saudi Dent J. 2016;28(1):36-43.

5. Bergh A, Van Staden C, Joubert P, Krüger C, Pickworth G, Roos J, et al. Medical students' perceptions of their development of "soft skills" Part II: The development of "soft skills" through ' guiding and growing'. South African Fam Pract. 2006;48(8):15a-15d.

6. Chua CJE, Chuatoco IAG, Mariz A, Peña C Dela, Jimenez DLF. The influence of participation in extracurricular activities to the employability of Industrial Engineering graduates of one Private University in the Philippines. Asia Pacific J Multidiscip Res. 2017;5(2):163-70.

7. Norafifah AS, Saat NZM, Aishah HS, Devanthini DG, Juliana S, Noryantima A, et al. Relationship between generic skills, academic performance and stress level among Undergraduate Students. Asian J Appl Sci. 2016;9(2):70-4.

8. Bakoban RA, Aljarallah SA. Extracurricular activities and their effect on the students grade point average: Statistical study. Educ Res Rev. 2015;10(20):2737-44.

9. Lumley S, Ward P, Roberts L, Mann JP. Self-reported extracurricular activity, academic success, and quality of life in UK medical students. Int J Med Educ. 2015;6:111-7.

10. Slade AN, Kies SM. The relationship between academic performance and recreation use among first-year medical students. Med Educ Online. 2015;20(1):1-8.

11. Urlings-Strop LC, Themmen APN, Stegers-Jager KM. The relationship between extracurricular activities assessed during selection and during medical school and performance. Adv Heal Sci Educ. 2017;22(2):287-98.

12. Elias H, Ping WS, Abdullah MC. Stress and academic achievement among undergraduate students in Universiti Putra Malaysia. Procedia-Social Behav Sci. 2011;29:29646-55.

13. Shamsudin S, Ismail SF, Al-Mamun A, Nordin SKBS. Examining the effect of extracurricular activities on academic achievements among the public university students in Malaysia. Asian Soc Sci. 2014;10(9):171-7.

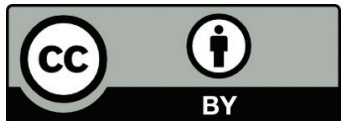

This work is licensed under a Creative Commons Attribution 